\title{
Management of the Lower Urinary Tract Symptoms (LUTS) due to Benign Prostatic Hyperplasia (BPH), with Terazosin
}

\author{
R M MUBEEN N AHMAD M SHAHZAD MNAWAZ MAKBAR \\ Department of Urology, Distt. Headquarter Hospital, Vehari \\ Correspondence to Dr. Rana Muhammad Mubeen,rmm_sb@yahoo.com
}

Objective: This study was designed to assess the efficacy, safety and compliance of terazosin in the management of lower urinary tract symptoms due to benign prostatic hyperplasia. Patients and methods: Study was conducted in the department of urology, DHQ Hospital Vehari, in about 1-year i-e from July 2004 to June 2005. Sixty patients with an age range of 45-85 years were included in the study. Data was collected prospectively. Patients were assessed according to the international prostate symptom score (I-PSS) at the start of study, during follow up and at the end of study. Results: Out of sixty patients, fifty-two were able to complete the study. It was observed that most of the patients obtained a significant decrease in the prostate symptoms score and improvement in QoL score, with only a few side effects.Conclusion: Terazosin is a safe and effective treatment for BPH with good compliance.

Key words: $\quad$ BPH, I-PSS, Terazosin, Selective $\alpha$-1-blocker.

$\mathrm{BPH}$ is the most common problem of the old age in urological practice. It is the most common cause of LUTS in men aged $>50$ years and rarely occur before the age of 40 years. It affects about $8 \%$ of men in $4^{\text {th }}$ decade, $50 \%$ of men ageing 60 years, rising to $88 \%$ in men aged 80 years and $90 \%$ in the $9^{\text {th }}$ decade. Out of these $\mathrm{BPH}$ patients $\approx$ $25 \%$ of men will require treatment by the age of 80 years ${ }^{1,2}$.

$\mathrm{BPH}$ is a proliferative process that involves both the stromal and epithelial elements of the prostate ${ }^{3,4}$. Its clinical manifestations include obstructive and irritative lower urinary tract symptoms, urinary retention, UTI, and haematuria ${ }^{5}$. In most men with this disorder, the goal of therapy is to relieve bothersome urinary symptoms.

Although prostatectomy has been a widely accepted treatment for symptomatic $\mathrm{BPH}$, this surgical procedure may fail in up to $20 \%$ of men,' will need to be repeated within 8 years in $15 \%$ of men, and is associated with complications such as impotence $10 \%$, urinary tract infections $8 \%$, epididymitis $5 \%$ and in $3 \%$ the urinary incontinence 6 . This leads to the desire of non-operable measures especially pharmacological therapy. Four groups of drugs are currently used in the conservative management of BPH. These are $\alpha-1$ adrenoceptor antagonists, $5 \alpha$ reductase inhibitors, phytotherapy and polyenic macrolides. Prazocin was a selective $\alpha-1$ adrenoceptor blocking agent. Terazosin is one of the second generation selective $\alpha-1$ adrenoceptor antagonist.

Caine, has suggested that obstruction secondary to $\mathrm{BPH}$ occurs because of two factors; a dynamic (smooth muscle) component and a mechanical (adenoma) component. Alpha 1-blockers act on the dynamic component of obstruction by decreasing the sympathetically controlled tone of prostatic smooth muscle $^{7}$.

Our aim of the study wás to assess the efficacy, safety and compliance of terazosin in the management of lower urinary tract symptoms due to benign prostatic hyperplasia.

\section{Patients and Methods:}

This study has been conducted in the department of urology, DHQ Hospital Vehari, in about 1-years i-e from July 2004 to June 2005.All patients were seen in urology OPD. Total number of patients included in the study was 60. Data was collected prospectively. Diagnosis about LUTS due to benign prostatic hyperplasia was made clinically in OPD after a detailed history, general \& systemic physical examination, DRE (digital rectal examination) and some basic investigations. In this study we only included the patients having LUTS secondary to $\mathrm{BPH}$. Patients were informed about the disease and its management options in detail and only those patients were included in the study who opted management of their symptoms with terazosin. The salient inclusion criteria were patient age $>45$ years, post void residual urine (PVRU) $<100 \mathrm{ml}$, symptoms of BPH sufficiently bothersome to warrant medical therapy. The salient exclusion criteria were clinical or laboratory evidence of prostate cancer, known diabetic, medically treated hypertension, primary neurological disorder, urinary tract infection, renal or hepatic insufficiency, orthostatic hypotension, prior prostatectomy, vesical stone and urethral stricture disease. Thorough assessment of obstructive and irritative symptoms was made while screening the patients. Patients were assessed according to the international prostate symptom score (I-PSS).

Terazosin was administered to all patients who quantified for the clinical trial. They received an initial dose of $1 \mathrm{mg}$ once daily for seven days and then a dose of $2 \mathrm{mg}$ per day for the next seven days. If the drug was well tolerated the dose was titerated to $5 \mathrm{mg}$ once daily. The treatment duration was 6 months. Patients were assessed at $0,14 \& 42$ days and then after every month for total of 6 months. Each patient completed the I-PSS questionnaire and quality of life score (QoL). Blood pressure, heart rate, breathing rate were measured at each follow up. DRE was done at the first and final visit. Apart from clinical history 
and examination the laboratory tests, urine analysis, urine culture, PSA(prostate specific antigen), $\mathrm{CBC}$ (complete blood count), RFTs (urea \& creatinine) were also considered at subsequent visits. The kidneys, urinary bladder, prostate adenoma volume and PVRU were assessed ultrasonographically.

\section{Results:}

A total of 60 patients with an age range of $45-85$ years, given consent to participate in this study. Out of these, 52 patients were able to complete the study. Three patients failed to attend the clinic and were lost to follow up. Two patients developed urinary retention during the treatment and underwent TUR-P. One patient was suspected to have carcinoma prostate on screening after 3 months and was excluded from the study. One patient discontinued the treatment saying that now he is okay without medicine Another one refused the treatment because of the side effects of medicine and opted for surgery.

Baseline clinical symptoms of all 60 patients entering the study are summarized in table-I, which shows the number of patients and their relative percentage in various columns of I-PSS score at the beginning of the study.

Table: 1 I-PSS at the beginning of trial $(n=60)$

\begin{tabular}{|c|c|c|c|c|c|c|}
\hline Score & 0 & 1 & 2 & 3 & 4 & 5 \\
\hline $\begin{array}{l}\text { Frequency of micturition } \\
\text { within two hours }\end{array}$ & 0 & 0 & $6(10 \%)$ & $32(53.33 \%)$ & $12(20 \%)$ & $10(16.66 \%)$ \\
\hline Urgency of micturition & 0 & $4(6.66 \%)$ & $10(16.66 \%)$ & $13(21.66 \%)$ & $25(41.66 \%)$ & $8(13.33 \%)$ \\
\hline Nocturia & & $2(3.33 \%)$ & $5(8.33 \%)$ & $31(51.66 \%)$ & $12(20 \%)$ & $10(16.66 \%)$ \\
\hline Poor stream & 0 & $6(10 \%)$ & $14(23.33 \%)$ & $16(26.66 \%)$ & $20(33.33 \%)$ & $4(6.66 \%)$ \\
\hline Strain to begin urination & 0 & $5(8.33)$ & $15(25.0 \%)$ & $12(20.0 \%)$ & $22(36.66 \%)$ & $6(10 \%)$ \\
\hline Intermittency & & $4(6.66 \%)$ & $8(13.33 \%)$ & $14(23.33 \%)$ & $20(38.46)$ & $14(23.33 \%)$ \\
\hline $\begin{array}{l}\text { Sense of incomplete bladder } \\
\text { voiding }\end{array}$ & 0 & $7(11.66 \%)$ & $17(28.33 \%)$ & $22(36.66 \%)$ & $10(16.66 \%)$ & $4(6.66 \%)$ \\
\hline
\end{tabular}

The symptomatic improvement assessed at the end of six months using I-PSS was significantly greater with terazosin. The results of all 52 patients who completed the study are elaborated in table-II.

Table:I1 I-PSS at the end of trial $(\mathrm{n}=52)$

\begin{tabular}{|c|c|c|c|c|c|c|}
\hline Score & 0 & 1 & 2 & 3 & 4 & 5 \\
\hline $\begin{array}{l}\text { Frequency of } \\
\text { micturition within } \\
\text { two hours }\end{array}$ & $7(13.46 \%)$ & $6(11.54 \%)$ & $\begin{array}{c}9(17.30 \%) \\
.\end{array}$ & $18(34.61 \%)$ & $7(13.46 \%)$ & $5(9.61 \%)$ \\
\hline $\begin{array}{l}\text { Urgency of } \\
\text { micturition }\end{array}$ & $18(34.61 \%)$ & $19(36.53 \%)$ & $8(15.38 \%)$ & $6(11.54 \%)$ & $1(1.92 \%)$ & 0 \\
\hline Nocturia & $20(38.46 \%)$ & $12(23.07 \%)$ & $8(15.38 \%)$ & $6(11.54 \%)$ & $4(7.69 \%)$ & $2(3.85 \%)$ \\
\hline Poor stream & $5(9.61 \%)$ & $10(19.23 \%)$ & $16(30.76 \%)$ & $13(52 \%)$ & $7(13.46 \%)$ & $1(1.92 \%)$ \\
\hline $\begin{array}{l}\text { Strain to begin } \\
\text { urination }\end{array}$ & $4(7.69 \%)$ & $9(17.30 \%)$ & $17(32.69 \%)$ & $10(19.23 \%)$ & $8(15.38 \%)$ & $4(7.69 \%)$ \\
\hline Intermittency & $14(26.92 \%)$ & $15(28.85 \%)$ & $9(17.31 \%)$ & $6(11.54 \%)$ & $5(9.62 \%)$ & $3(5.77 \%)$ \\
\hline $\begin{array}{l}\text { Sense of incomplete } \\
\text { bladder voiding }\end{array}$ & $6(11.54 \%)$ & $11(21.15 \%)$ & $7(13.46 \%)$ & $19(36.54 \%)$ & $7((13.46 \%)$ & $2(3.85 \%)$ \\
\hline
\end{tabular}

Table:-III Side effects of terazosin $(\mathrm{n}=52)$

\begin{tabular}{lcc}
\hline Adverse events & No. of patients & Percentage \\
\hline Dizziness & 1 & $1.92 \%$ \\
Headache & 1 & $1.92 \%$ \\
Asthenia & 1 & $1.92 \%$ \\
Postural hypotension & 2 & $3.85 \%$ \\
Total & 5 & $9.61 \%$ \\
\hline
\end{tabular}

\section{Discussion:}

The use of alpha adrenergic blockade to treat men with symptomatic benign prostatic hyperplasia is based on the hypothesesis that the disorder arises from bladder-outlet obstruction and that 40 percent of cellular volume of the hyper plastic prostate is made up of smooth muscle ${ }^{8}$, whose tension is mediated by alpha-1 adrenoceptors'. Therapy with alpha-1 adrenergic-antagonist drugs such as terazosin has been found to be safe and effective in men with benign prostatic hyperplasia ${ }^{10.11,12}$, a finding that our study confirmed. There was a significant decrease in I-PSS score after six months of terazosin therapy, changes nearly identical to those observed in an earlier clinical trial of terazosin at the same dose.

These results suggest that the treatment for BPH with terazosin is quite safe and effective. The risk of adverse events is low (about 9\% ), compareable with other studies $^{13.14}$. There is a good therapeuitic effect, as shown by the decrease in LUTS, improved QoL and smaller PVRU at a dose of $5 \mathrm{mg}$ /day.

The aim of this mode of treatment is not to cure $\mathrm{BPH}$ but to treat a very large number of patients who suffer from troublesome symptoms but do not otherwise need operation, and also those who are in waiting list of surgery for $\mathrm{BPH}^{15}$. 
The cardiovascular safety profile fascillitates the prescription of terazocin in patients receiving concomitant antihypertensive medications and in older patients in which the prevalence of orthostatic hypotension is high ${ }^{16}$.

The results of our study have also shown that the IPSS symptom score for both obstructive and irritative symptoms were significantly improved with terazocin. It was also observed in our study that the symptomatic improvement was associated with a significant improvement in patients quality of life.

\section{Conclusion:}

The main aim of this study was to assess the efficacy, safety and compliance of terazocin in the treatment of patients with symptomatic benign prostatic hyperplasia. The results of this study depicts that terazocin is a safe and effective drug in the management of LUTS due to enlarged prostate. This also suggest that men with symptomatic BPH who lack absolute indications for surgical intervention and contraindications for alpha blockade may be offerd this treatment alternative.

\section{References:}

1. Berry SJ, Coffey DS, Walsh PC, et al: the development of human benign prostatic hyperplasia with age. J Urol 1984:132;474-9.

2. Hillman AL, Shwartz JS, William MK et al. The cost effectiveness of terazosin and placebo in the treatment of moderate to severe benign prostatic hyperplasia. Urology.1994; 43: 621-8.

3. Bartsch G, mullers HR, Oberhozer M, Rohr HP. Light microscopic stereological analysis of the normal human prostate and of benign prostatic hyperplasia. J Urol. 1979; 122:487-91.

4. Shapiro E, Hartanto V, Lepor H. The response to alpha blockade in benign prostatic hyperplasia is related to the percent area density of prostate smooth muscle. Prostate 1992; 21:297-307.

5. Madsen FA, Bruskewitz RC. Clinical manifestations of benign prostatic hyperplasia. Urol Clin. North Am 1995; 22:291-8.
6. Lepor $\mathrm{H}$. The emerging role of alpha antagonists in the therapy of benign prostatic hyperplasia. J Androl. 1991; 12:389-94.

7. Cain M. Alpha adrenergic blockers for the treatment of benign prostatic hyperplasia. Urol.Clin. N. Amer.,1990;17:641-49.

8. Lepor $\mathrm{H}$. The role of alpha blockade in the therapy of benign prostatic hyperplasia. In: Lepor $\mathrm{H}$, Lawson RK, eds. Prostate diseases. Philldelphia: W. B. Saunders, 1993: $170-81$.

9. Gup DI, ShapiroE, Baumann M, Lepor H. Contractile properties of human prostate adenomas and the development of infravesical obtruction. Prostate 1989; 15:105-14.

10. Lepor H, Auerbach S, Puras-Baez A, et al. A randomized, placebo-controlled multicenter study of the efficacy and safety of terazosin in the treatment of benign prostatic hyperplasia. J Urol 1992;148:1467-74.

11. Brawer MK, Adams G, Epstien H, Terazosin benign prostatic hyperplasia study group. Terazosin in the treatment of benign prostatic hyperplasia. Arch Fam Med 1993;2:929-35.

12. Kawabe K, Ueno A, Takimoto Y, Aso Y, Kato H. Use of alpha-1 blocker in the treatment of benign prostatic hyperplasia. J Urol 1992;148:908-11.

13. E. Miekos, Z. Trzepizur, W. Rozanski, et al.The efficacy of terazosin for treating benign prostatic hyperplasia: a multicentre clinical trial. British Journal of Urology.2002; 89(7): 771-72.

14. S. Saleem A. Jaffery, M. Saleem Akhtar et al. Efficacy, safety and compliance of terazosin in the treatment of patients with symptomatic benign prostatic hyperplasia. JAMC. 2000; 12(2): 02-06.

15. Aslam M, Qureshi MA, Yousuf M, Alam K. How to achieve a catheter free patient waiting for elective prostate surgery. Ann. Abbasi Shaheed Hosp Kar Med Dent Coll 1999;4: 146-7.

16. R. S. Kirby. Terazosin in benign prostatic hyperplasia: effects on blood pressure in normotensive and hypertensive men. British Journal of Urology.1998; 82: 373-79. 